DOI: $10.20472 / B M .2017 .5 .2 .003$

\title{
RESILIENCE IN DYNAMIC COMPLEX ENVIRONMENTS: WILLFUL ADAPTABILITY AND COPABILITY
}

\section{KURT MOTAMEDI}

\begin{abstract}
:
Social systems respond to their environments along two mutually interdependent processes through adaptation and coping. Adaptability is the capability to understand and make necessary adjustments to fit with the environment by making requisite internal changes and responding to and acting in the environment. Coping is the internal processes which help determine how the organization maintains its sense of identity and wholeness in view of the externally and internally induced changes. As the environment becomes more diverse, differentiated and complex, the dynamic changing environment creates conditions for some organizations with the right internal resources and capabilities to survive and prosper while others with less coping abilities (copabilities) may stagnate, become obsolete or lose their sense of wholeness and identity. The will to succeed is a key factor in creating and maintaining a robust balance of adapting and coping forces for building and maintaining a well performing resilient social system. The article explores three key factors underlying resilience; adaptability, copability, and the will to succeed, The article proposes that resilience is a determinant component of social systems effectiveness, survival and revitalization.
\end{abstract}

\section{Keywords:}

Resilience, Adapting, Coping, Willfulness, Will To Succeed, Adaptability, Copability, Dynamic Complexity, Change

JEL Classification: L20, L29, Z00

\section{Authors:}

KURT MOTAMEDI, Pepperdine University , United States, Email: Kurt.Motamedi@Peppperdine.edu

\section{Citation:}

KURT MOTAMEDI (2017). Resilience in Dynamic Complex Environments: Willful Adaptability and Copability . International Journal of Business and Management, Vol. V(2), pp. 29-39., 10.20472/BM.2017.5.2.003 


\section{Introduction}

Rapid and unanticipated life changes and complexities accompany opportunities and threats for individuals, groups, organizations, communities and transorganizations. In response, resilient social systems manage to survive and prosper through building, developing, improving and sustaining their abilities and resources to take advantage of change created opportunities in view of risks and threats. Low resilient systems falter, lose grounds and eventually become extinct. Resiliency is a key success factor for surviving and prospering in turbulent complex environments. Enduring social systems exhibit resilience in view of repeated challenges. They are able to capitalize on opportunities without losing a sense of their core values and direction. They harness the will to succeed through ability to adapt externally and to cope with internal adjustments. Knowledge of key components of resiliency help develop critical resources, attitudes, skills and competencies not only to deal with obstacles and changes of all size and magnitude, but capacity to create success.

For example, successful organizations value executives and teams with qualifications and abilities to overcome challenges and turn threats or unfavorable situations into positive outcomes. They favor the abilities that overcome disabling conditions whether organizational, personal, competitive, socio/economic, physical in view complex changing environments. They reward performers who exhibit resilient qualities and drive long term organizational, team and personal success capitalizing on opportunities in view of adversity. They overcome and endure difficult and even volatile circumstances. Resilient organizations and people succeed in view of circumstances that would set back and cause many ordinary organizations and leaders to fail.

Many exemplary societal contributors have faced and overcome difficult life experiences. Life challenges and early bitter experiences have led to their mastery of resilient skills. Executives of many thriving companies have endured through plethora of difficult and challenging situations. Alex $\mathrm{X}$, the founder of a mid-size growing company, was abandoned as a child with his two sisters. He was left to care for them at age 10 . He could not attend schools and would beg for food to feed his siblings. A few years ago when he was attending Pepperdine's Presidents and Key Executives MBA program he recalled that although his childhood situation was hopeless and helpless, he was driven to overcome it. A well-documented touching experience is told by Victor Frankel of his horrific experiences of survival in concentration camps during World War II. Similar experiences are shared by companies such as Apple, Intel, Amazon and IBM. These companies are among many that have experienced their market value almost disappear, at one time, but overcame the setbacks and succeed beyond what was anticipated. The detail journals of the surviving members of Donner Party expedition trapped in the high Sierras during the harsh winter of 1848 , on route to California, tell a story of resilience 
and failures by members of the expedition. The men of that event resorted to violence and cannibalism and many did not survive. However, the women and their children overcame the long and threatening hostile situation. They protected their young and themselves from imminent death from cold and starvation and did not engage in violence and cruelty as men did. All women survived exhibiting superior resilience. The tragic 9/11 disaster destroyed and disrupted many lives. Some firms devastated by the attack survived well and prospered while others disappeared. One may argue that the victory of allied forces and Britain during WWII in the face of the dominant well equipped and trained enemy is a familiar case for resiliency exhibited by Winston Churchill. Overcoming bitter and major setbacks in the face of hostility requires resiliency. The enduring social systems are resilient and capable to overcome adversity.

These observations and personal experiences offer compelling reasons to explore and understand the underlying common factors that contribute positively to resiliency across all types of social systems: Individuals, groups, organizations and transorganizations. After all, human history is populated by enduring social systems succeeding through resiliency.

\section{Resilience}

The characteristics that make resiliency possible are essential and common in living systems. Resiliency is about success in facing short or long term setbacks and exposure to often untenable conditions challenging and threatening survival and progress. Gordon (1996) states that resilience is the ability to thrive, grow and increase competence in the face of adverse circumstances. Luthar, Cicchetti and Becker (2000) and Cicchetti and Becker (2013) view resilience as a construct connoting the maintenance of positive adaptation by individuals despite experiences of significant adversity. Gordon and Coscarelli (1996), and Greene, Galambos, and Lee (2004) view resilience as the ability to thrive, grow and increase competence in the face of adverse circumstances. Considering resiliency in the context of large social system, Cordina (2004a, b) presents a conceptual framework applicable to economic resilience of nations, and discusses that saving and capital formation in an economy, in response to a situation of vulnerability, can be important sources of resilience.

We believe there is more to resiliency. Resiliency is a social system's ability to: (1) adapt to the external conditions whether favorable or unfavorable, (2) cope with internal stresses and disharmonies in circumstances, and (3) the will to develop success strategies and acumen in execution through effective action that assure survival and success in view of opportunities or threats. Resiliency required conditions could be long or short term, physical, psychological, social, technical, financial, biological and economical. It may be a one-time event, infrequent, frequent or chronic. 
Resilience requires integration and alignment of adaptability, which relates to a social system's ability to deal with its external environment and attain environmental relevance; and copability, which reflects a system's ability to deal with and maintain a viable internal environment and a sense of identity (Motamedi, 1977, 1982). A resilient social system consciously or unconsciously practices and uses these two sets of processes propelled by the will to succeed.

The third key factor, the will to succeed, is a key element of resiliency. Strategy is an instrument of the will as a rational process to select the best course of action to achieve balance between external and internal conditions toward achieving desired outcomes. Effective strategies are built on the requirement for adaptation to external environment and internal management of changes and effective coping. Strategy execution can help build resilience if it is grounded in adaptive action responding to external environment dynamic conditions and for coping to maintain a sense of identity and internal well-being. A system with the abilities, resources, and competencies to adapt and cope must have the will to succeed. The will to succeed provides direction and motivation to develop effective strategies, execute efficiently and build resilience.

The will to succeed can bring about motivation to overcome obstacles and setbacks externally and internally. It is a primary element of resilience. Adaptation is basic to a social system's resilience in dealing with its external environment events and changes. Coping is a necessary internal adjusting process for maintenance and development of the system's sense of self and identity. The will to succeed provides motivation for adapting and coping. It provides efficacy for overcoming challenges and capitalizing on opportunities externally and internally.

In the following, we expand on these principle components of resilience: adaptability, copability and will.

\section{Adaptability}

Resilient social systems can deal with the changes, complexities and conditions of their external environment. Piaget (1932) viewed adaptation as the equilibrium toward which the organism moves as the result of the interaction between its internal and external environment. Fromm (1941, 15-16) classified adaptation into static and dynamic:

By static adaptation we mean such an adaptation to patterns that leaves the whole character structure unchanged and implies only adoption of a new habit. An example of this kind of adaptation is the change from the Chinese habit of eating [with chop sticks] to the Western habit of using fork and knife. A Chinese coming to America will adapt himself to this new pattern, but this adaptation in itself has little effect on his personality; it does not arouse new drives or character traits. By 
dynamic adaptation we refer to the kind of adaptation that occurs, for example, when a boy submits to the commands of his strict and threatening father - being too afraid of him to do otherwise - and becomes a "good boy." While he adapts himself to the necessities of the situation, something happens in him. He may develop an intense hostility against his father, which he represses, since it would be too dangerous to express it or even to be aware of it. This repressed hostility, however, though not manifest, is a dynamic factor in his character structure. It may create new anxiety and thus lead to still deeper submission; it may set up a vague defiance, directed against no one in particular but rather toward life in general. This kind of adaptation creates something new in him, arouses new drives and new anxieties

Sterman, J. (2000) explores issues surrounding adaptive thinking in face of complexity. Tushman and Anderson (1986) focus on adaptation in face of technological discontinuities in dynamic organizational environments. A resilient social system attains control over its environment, via adaptive function, or modifies its internal structure and processes to meet the requirements of its external environment. Resiliency requires a system's adaptability to enable it to interact with the environment in such a way as to ensure its own survival and success. This is done by changing (1) the external environment, (2) its internal environment of the system to meet the requirements of the external environment, (3) both external and internal environments for a fit. Adaptability may involve a plethora of approaches. Some are listed below.

1. Avoiding: Taking measures to shun difficult or unproductive environments

2. Compliance: Going along with the changes and making the needed internal changes to comply

3. Compromising: Negotiate and incorporate changes that are feasible

4. Collaborating: Reach for win-win solutions where both external and internal requirements are met

5. Controlling: Reach out externally to manage the flow and intensity of changes generated

6. Pre-empting: Anticipate and make the changes prior to formulation of external requirements

7. Resisting: Expend energy to divert and reduce the direction or intensity of change

8. Opposing: Take an adversarial position to the changes and expend resources to divert it

9. Fighting: Take a hostile position to the changes and expend energy to eradicate them and win

10. Abandoning: Evacuating and leaving environments that are hostile and unproductive 


\section{Copability}

Copability is a social system's ability to maintain its internal wellbeing, conserve, renew and synthesize its components. Copability helps develop and maintain a system's core competencies and resources. It helps develop and preserve its sense of identity, integrity and ability to hold its own. It brings together disparate internal parts, integrates them, creates synergies and empowers the system and its subsystems into a functioning cohesive intelligent whole. In gestalt theory (Kofka, 1935), the notion of pragnanz or unity, uniformity, good continuation captures some aspects of copability. Bradley and Calvin (1956) refer to Le Chatelier's principle of system embedded forces that restore the system as closely as possible to its original state. Festinger (1957) identifies this internal stabilization as "dissonance reduction" which deals with any change and disruption of the internal component parts and reduces the effect of change imposed by internal stress, strain and disharmony. Greene, Galambos and Lee (2004) explored and studied resilience along conceptualizations of conditions practitioners thought act as buffers to life stress and contribute to coping and resilience. Dutton and Dukerich (1991) explore issues of image and identity in adaptation process.

Copability also involves a system's ability to deal with the change of own self-concept, core cognitive processes (Kolasa, 1969) and accompanying emotions. Copability is proactive in diagnosing the internal change-induced dislocations related to structure, processes, technology, values, needs and purposes, feelings of disharmonies within and among the subparts and to address them. Copability may involve a plethora of approaches. Some are listed below.

1. Resolving: Finding solutions to the change requirements and associated internal disharmonies and tensions

2. Arresting: Freezing the size and level of change and its impact on internal functioning

3. Reframing: Cultivating new ways of thinking about the issues for effective response

4. Suppressing: Hold back dealing with the concerns until such time that they can be dealt with

5. Seeking support: Acquire help and nurturance of others to address the internal issues

6. Restructuring: Rearranging, aligning and rationalizing internal resources, activities and processes

7. Learning: Gaining knowledge, understanding and new insights into the nature and scope of issues and solutions

8. Reassuring: Regaining self confidence in one's self to effectively resolve the issues 
9. Renewing: Acquiring new skills, behaviors, attitudes and competencies to handle the issues

\section{Adaptability and Copability Compared}

Adaptability constitutes efforts and pattern of activities that deal with external environment conditions, requirements and demands. It is focused on ways of anticipating and addressing external changes and complexities. Copability consists of efforts (conscious or unconscious) to maintain and develop an internal environment and a sense of identity and wellbeing. Both have important roles in developing, enhancing and sustaining social systems' resiliency. A comparison of these two key elements of resilience is presented in Table 1.

\section{TABLE I Adaptability and Copability Compared}

\section{Adaptability}

\section{Copability}

\begin{tabular}{|c|c|}
\hline $\begin{array}{l}\text { Provides relevancy and fit with external } \\
\text { environment }\end{array}$ & $\begin{array}{l}\text { Provides internal integration within the } \\
\text { internal environment }\end{array}$ \\
\hline $\begin{array}{l}\text { Involves boundary spanning and } \\
\text { contraction. }\end{array}$ & Involves internal maintenance within. \\
\hline $\begin{array}{l}\text { Directed to achieve deliberate overarching } \\
\text { purposes in the external environment. }\end{array}$ & $\begin{array}{l}\text { Directed to achieve conscious and } \\
\text { unconscious sense of internal dynamics, } \\
\text { values and well being }\end{array}$ \\
\hline $\begin{array}{l}\text { Determined by external environment and } \\
\text { others. }\end{array}$ & $\begin{array}{l}\text { Determined by internal environment and } \\
\text { self. }\end{array}$ \\
\hline $\begin{array}{l}\text { Involves trans-boundary change } \\
\text { (importing \& exporting change across } \\
\text { boundaries) }\end{array}$ & $\begin{array}{l}\text { Involves intra-system changes (renewal } \\
\text { development of competencies, their } \\
\text { maintenance } \\
\text { and emotional wellbeing) }\end{array}$ \\
\hline Search is outward directed externally & Search is inward and introspective \\
\hline $\begin{array}{l}\text { Temporal orientation is from future to the } \\
\text { present }\end{array}$ & $\begin{array}{l}\text { Temporal emphasis is from past to the } \\
\text { present. }\end{array}$ \\
\hline Spatial emphasis is about "there." & Spatial emphasis is about "here." \\
\hline $\begin{array}{l}\text { Process function is dominated by sensory } \\
\text { and empirical thinking }\end{array}$ & $\begin{array}{l}\text { Process function is dominated by intuiti } \\
\text { and feeling, and speculations }\end{array}$ \\
\hline
\end{tabular}




\begin{tabular}{|l|l|}
\hline $\begin{array}{l}\text { Thrust is toward the external environment } \\
\text { change of internal environment to fit the } \\
\text { external conditions }\end{array}$ & $\begin{array}{l}\text { Thrust is toward maintenance, alignment } \\
\text { or } \\
\text { integration, renewal and retention of } \\
\text { internal culture, processes and parts as a } \\
\text { whole. }\end{array}$ \\
\end{tabular}

\section{The Will to Succeed}

The force which propels social systems to develop and use appropriate levels of adaptability and copability is the will to succeed. It is the value-based will to move toward a purpose and take action. The will drives overcoming setbacks as well as using the events either desirable or unwelcoming as opportunities to gain strategic and competitive advantage (e.g., during the times competitors are embroiled in trauma and have low resiliency). The determination or resolve to succeed is a powerful motivating force. It involves developing the strategy with consideration of external and internal conditions for making progress toward achieving the overarching purpose, vision, mission, values and ideals of the social system through effective execution.

The will to succeed is an important factor for creating and maintaining integration and alignment of adaptability and copability. It is the driving force of resiliency and for a social system to manage these two sets of interacting processes. Will is an active essential ingredient for creating, renewing and balancing these factors for success. It requires thinking and developing strategies that are deliberate, rational, and generating, selecting and implementing viable courses of action to achieve requirements for effective adaptation. The will to succeed is a key element of resiliency. A social system with requisite abilities, resources, and competencies to adapt, cope, strategize and execute can assure long term resilience with a measured values-based will to succeed.

The will to succeed plays a critical role in acquiring, developing, sustaining adaptability, copability and the associated competencies. High resilient social systems possessing all three abilities and attributes comprising of (1) strong will to succeed, (2) high adaptability and (3) high copability are exposed to less risk of failure in face of turbulent environments, adverse conditions and even discontinuous change. A social system with low adaptability and low copability and a confused will of success may not gain the requisite level of resiliency to survive and prosper. 


\section{Transformative Resiliency}

As the environment changes, customer needs, and stakeholder priorities change, social systems evolve and transform. Often, the transformation follows an evolutionary life cycle of development, growth, maturity and decline. In each phase there are challenges to be met. The will to succeed and capabilities for adaptation and coping are an important element that leads to resiliency and staying power of the system. Some social systems may transform to new forms and recreate themselves. Innovation driven resiliency may lead to major system transformations. IBM was transformed from a large scale computer company to a professional service company. Apple transformed to become a multifaceted technology company. These social systems transformed themselves by vacating low value environmental niches and move to more fertile niches. This is what we call Transformative resiliency which emerges out of creativity, innovation and entrepreneurship in addition to all three elements discussed above.

\section{Resilience Re-Conceptualized}

Resilience is a systems effort to respond to changing conditions, overcome adversity, and capitalize on opportunities. Transformative resiliency emerges from a system that is redefining and reconstituting itself. It may involve vacating impoverished niches in the environmental where the need for services are declining or have been eliminated and moving to niches where there is value in serving new stakeholders needs. Resilience is not responding to adverse conditions only. It is a process of renewal in response to the environmental shifts and change. The will to succeed, adaptability and copability are critical elements of resilience. Resilience is not only a reaction to chaos or catastrophe, it is also pro-active, involving anticipatory and willful adaptation and coping.

\section{Summary and Conclusion}

Resiliency is an important attribute of a social systems operating in dynamic complex environments. It is a key element of success that needs to be developed and renewed continuously as environments change. Forces of entropy both internal and those induced externally will require a social or living systems to develop the will to succeed, continually learn and develop their skills, competencies and resources to enhance their adaptability and copability.

The will for success along with abilities to understand and adapt to external dynamic complexities and making appropriate internal adjustments are critical factors for a social system to build resiliency. A major element of resilience is the will to succeed through planning, strategy and execution. All three sets of competencies are required for enduring 
success. Level one is the will. Without it success is uncertain. Level two is sustainable adaptability requiring understanding external environment dynamics and complexities that the social system must operate within. The third level is development and sustaining copability for developing and maintaining internal processes and assuring emotional, cognitive and social consistency. The likelihood of success increases when social systems, facing complex and dynamic circumstances, move forward with the strong will to succeed, adapt and maintain their sense of well-being and identity.

\section{References}

Bradley, D. F. and Calvin, M, (1955) Behavior: Imbalance in A Network. O F Chemical Transformations. University of California Radiation Laboratory Printed: for the U. S. Atomic ... UCRLA 3203 Lawrence Livermore National Laboratory Yearbook of the Society for the Advancement of General System

Cordina, G. (2004a) “Economic Vulnerability, Resilience and Capital Formation.” In Lino Briguglio and

Eliawony J Kisanga eds, Economic Vulnerability and Resilience of Small States, Islands and Small States Institute and Commonwealth Secretariat.

Cordina, G. (2004b) "Economic Vulnerability and Economic Growth: Some Results from a Neo-Classical

Growth Modelling Approach," Journal of Economic Development, vol. 29:2, December.

Dutton, J.E., \& Dukerich, J.M. (1991). Keeping an eye on the mirror: image \& identity in organizational adaptation. Academy of Management Journal, 34, 517-554. https://doi.org/10.2307/256405

Festinger, L. A Theory of cognitive dissonance. Palo Alto, Calif.: Stanford University Press, 1957.

Fromm, E. (1941) Escape from freedom. New York: Rinehart and Winston.

Gordon, K. A. and Coscarelli, W. C. (1996), Recognizing and fostering resilience. Nonprofit Management Leadership, 35: 14-17. doi:10.1002/pfi.4170350906

Gordon (1995) states that resilience is the ability to thrive, grow and increase competence in the face of adverse circumstances. We believe there is more to resiliency.

Greene, R.; Galambos, C and Lee, Y. (2004) Resilience Theory: Theoretical and Professional Conceptualizations Journal of Human Behavior in the Social Environment Volume 8 - Issue 4 Pages 75-91 | Published online: 25 Sep 2008

Koffka, K. (1935) Principles of Gestalt psychology. New York: Harcourt, Brace and World, 1935.

Kolasa, B. J. (1969) Introduction to behavioral science for business. New York: John Wiley, 1969.

Luthar, S. S., Cicchetti, D. and Becker, B. (2000), The Construct of Resilience: A Critical Evaluation and Guidelines for Future Work. Child Development, 71: Issue 3, 543-562. doi:10.1111/14678624.00164

Piaget, J. (1932) The moral judgment of the child. New York: The Free Press, 1965 
Sterman, J. (2000). Business Dynamics: Systems Thinking for a Complex World. New York, Irwin/McGrawHill.

Tushman, M. L. and P. Anderson (1986). "Technological discontinuities and organizational environments." Administrative Science Quarterly 31: 439-465. https://doi.org/10.2307/2392832 